\title{
Taking care of the soldiers
}

\author{
Song Wan ${ }^{1}$, Zhao-Yun Cheng ${ }^{2}$ \\ ${ }^{1}$ Division of Cardiothoracic Surgery, The Chinese University of Hong Kong, Prince of Wales Hospital, Hong Kong, China; ${ }^{2}$ Department of \\ Cardiovascular Surgery, Fuwai Central China Cardiovascular Hospital, Zhengzhou 450046, China \\ Correspondence to: Song Wan, MD, FRCS. Division of Cardiothoracic Surgery, The Chinese University of Hong Kong, Prince of Wales Hospital, \\ Hong Kong, China. Email: swan@cuhk.edu.hk. \\ Provenance: This is an invited Editorial commissioned by the Section Editor Shu Chen (Department of Cardiovascular Surgery, Union Hospital, \\ Tongji Medical College of Huazhong University of Science and Technology, Wuhan, China). \\ Comment on: Brilakis ES, Edson R, Bhatt DL, et al. Drug-eluting stents versus bare-metal stents in saphenous vein grafts: a double-blind, randomised \\ trial. Lancet 2018;391:1997-2007.
}

Submitted Aug 30, 2018. Accepted for publication Sep 07, 2018.

doi: $10.21037 /$ jtd.2018.09.25

View this article at: http://dx.doi.org/10.21037/jtd.2018.09.25

Ischemic heart disease is the most common cause of death worldwide. Coronary artery bypass grafting (CABG) remains the cornerstone of treatment for patients with significant left-main or multi-vessel coronary lesions (1). Each year, at least half a million CABG operations are carried out worldwide. While the importance of arterial grafting can never be over-emphasized, particularly for the routine application of the left internal mammary artery (LIMA), the autologous saphenous vein graft (SVG) continues to be widely used conduit for CABG. However, the long-term success of surgical myocardial revascularization is limited by SVG failure. Given that more than half of the vein grafts are occluded by 10 years after CABG and the magnitude of this clinical problem will keep on increasing (2), the failure of SVG inevitably imposes a major burden on health care resources.

If "LIMA is the king," as every surgeon truly believes, then SVGs are the soldiers. In a war, soldiers usually die before the king, including in the metaphorical war against ischemic heart disease. Even though taking care of the SVG "soldiers" has been one of the top priorities in recent decades, the suboptimal patency of SVGs remains the Achilles heel of CABG. Despite multiple clinical trials, no specific pharmacological agents have been found that benefit early SVG remodeling or subsequent accelerated atherosclerosis (3). Novel therapeutic strategies are therefore urgently required (4).

Applying percutaneous coronary intervention technology with the use of drug-eluting stents (DES) or bare-metal stents (BMS) has become an increasingly common practice for the treatment of SVG stenosis (5). Nonetheless, which type of stent are the most appropriate remains largely unclear. Recently, two multicenter, randomized, controlled trials have provided some new insights into feasible choices for the treatment of SVG stenosis $(6,7)$. Brilakis and colleagues (6) revealed that the safety and efficacy of BMS and DES were equivalent for the treatment of de novo SVG stenosis more than 10 years after CABG. Interestingly, DES provided superior early patency in the treatment of aortocoronary SVG lesions at 1 year compared to BMS, but this advantage dissipated over 5 years (7). Such observations can certainly impact clinical decision making and costeffectiveness analyses. Taken these two timely investigations together, it actually makes a better sense since the mechanism involved in SVG failure is indeed very complex and time-dependant (Figure 1).

Central to late vein graft failure is the formation of a neointima, which usually occurs within 18 months after CABG. The formation of a neointima involves the replication of medial vascular smooth muscle cells that migrate across the internal elastic lamina to the intima, where they continue to proliferate and secrete extracellular matrix proteins. Thereafter, atherogenesis is superimposed on the neointima formation, which ultimately precipitates late thrombotic occlusion. There is a general consensus that the inhibition of neointima formation (i.e., vascular smooth muscle cell proliferation and migration) might reduce late vein graft failure. However, apart from aggressive 


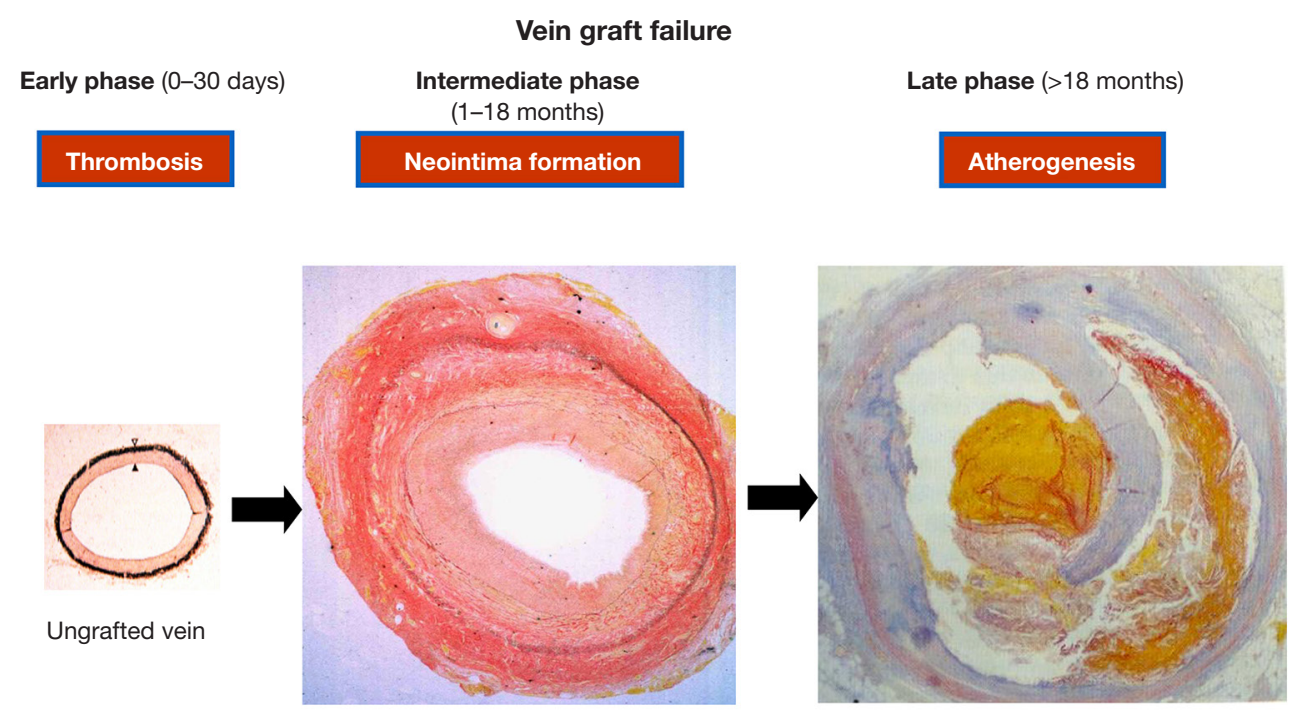

Figure 1 Natural history of vein graft thickening, atherogenesis, and late failure: timeline and possible mechanisms involved. Modified with permission from Wan S, Yim AP, Angelini GD, Jeremy JY. Novel strategies for the prevention of vein graft failure. In: He GW, editor. Arterial grafting for coronary artery bypass surgery, 2nd edition. Springer-Verlag: Singapore, 2006:303-10.

lipid lowering therapy in patients with dyslipidemia, no pharmacological intervention has so far been successful in treating late vein graft failure after CABG. Hence, the search for an effective pharmacological treatment for vein graft failure has become something akin to the "search for the holy grail".

Diverse approaches for preventing neointima formation have been investigated in recent decades, and some might constitute viable solutions to the problem. These approaches include the placement of external stents (8-10), treatment of vein grafts with cytostatic drugs (11-14), and gene transfer (15-18). These approaches, which investigate the etiology of vein graft biology, have all effectively inhibited neointima formation in a porcine model of vein into artery interposition grafting (11-18). The findings from these studies could suggest potentially useful strategies in the clinical treatment of vein graft disease. However, the extrapolation of experimental findings to clinical practice requires caution because it is common for drugs that are effective in animal models to be ineffective in human clinical trials. Vascular disease and associated risk factors are also absent in animal models, but in patients undergoing CABG, atherosclerosis of the coronary artery is invariably present. The risk factors for atherosclerosis and vein graft failure, including diabetes mellitus, hyperlipidemia, homocysteinemia, smoking, age, and gender, could thus render treatments derived from experimental models ineffective in people. Animal models with atherosclerotic disease and with the associated risk factors are needed.

Last but not least, the way that a piece of vein was harvested might be equally important, if not more important, in prevention of the late SVG failure. It is generally believed that the greater degree of trauma associated with SVG harvesting will translate into a higher rate of SVG failure. Hence, whether endoscopic vein harvesting is truly "minimally invasive" has been the focus of a heated debate. An earlier observation (19) indicated that endoscopic harvesting of SVG was independently associated with vein graft failure and adverse clinical outcomes. On the contrary, Souza and colleagues $(20,21)$ repeatedly demonstrated that SVG harvested with the surrounding tissue (i.e., the "no-touch" technique) can significantly improve its long-term patency result.

Each of these proposed strategies might alone be insufficient to prevent late vein graft failure but could be useful as a primary blockade of early neointima formation followed by the secondary administration of effective antiatherogenic drugs. This latter therapy should account for the presence of different risk factors and be adjusted accordingly. It is hopeful that the combination of several strategies to address the currently intractable problem of treating late vein graft failure could lead to an improved 
solution in the future (22). No doubt, even an incremental advancement in enhancing the durability of the SVG could positively impact millions of patients.

For surgical myocardial revascularization, the battle plan appears complex and time-consuming. The past decades have shown that unfortunately, there is no magic bullet for the treatment of late SVG failure. Nonetheless, the principle remains unchanged-like in any war, soldiers should be protected as much as possible.

\section{Acknowledgements}

Our previous research projects were supported by the Hong Kong Research Grants Council and the British Heart Foundation. We are particularly grateful to Professors Andrew H. Baker (University of Edinburgh, UK), Jamie Y. Jeremy and Sarah J. George (University of Bristol, UK) for their firm collaborations over the past decades.

\section{Footnote}

Conflicts of Interest: The authors have no conflicts of interest to declare.

\section{References}

1. Mohr FW, Morice MC, Kappetein AP, et al. Coronary artery bypass graft surgery versus percutaneous coronary intervention in patients with three-vessel disease and left main coronary disease: 5-year follow-up of the randomised, clinical SYNTAX trial. Lancet 2013;381:629-38.

2. Campeau L, Enjalbert M, Lespérance J, et al. Atherosclerosis and late closure of aortocoronary saphenous vein grafts: sequential angiographic studies at 2 weeks, 1 year, 5 to 7 years and 10 to 12 years after surgery. Circulation 1983;68:II1-7.

3. Jeremy JY, Zacharowski K, Shukla N, et al. Pharmacological strategies aimed at reducing complications associated with coronary artery bypass graft surgery. Curr Opin Pharmacol 2012;12:111-3.

4. Wan S, George SJ, Berry C, et al. Vein graft failure: current clinical practice and potential for gene therapeutics. Gene Ther 2012;19:630-6.

5. Dehmer GJ, Weaver D, Roe MT, et al. A contemporary view of diagnostic cardiac catheterization and percutaneous coronary intervention in the United States: a report from the CathPCI Registry of the National Cardiovascular Data Registry, 2010 through June 2011. J Am Coll Cardiol
2012;60:2017-31.

6. Brilakis ES, Edson R, Bhatt DL, et al. Drug-eluting stents versus bare-metal stents in saphenous vein grafts: a doubleblind, randomised trial. Lancet 2018;391:1997-2007.

7. Colleran R, Kufner S, Mehilli J, et al. Efficacy over time with drug-eluting stents in saphenous vein graft lesions. J Am Coll Cardiol 2018;71:1973-82.

8. Angelini GD, Izzat MB, Bryan AJ, et al. External stenting reduces early medial and neointimal thickening in a pig model of arteriovenous bypass grafting. J Thorac Cardiovasc Surg 1996;112:79-84.

9. Hu J, Wan S. External support in preventing vein graft failure. Asian Cardiovasc Thorac Ann 2012;20:615-22.

10. Mawhinney JA, Mounsey CA, Taggart DP. The potential role of external venous supports in coronary artery bypass graft surgery. Eur J Cardiothorac Surg 2018;53:1127-34.

11. Wan S, Yim AP, Johnson JL, et al. The endothelin-1a receptor antagonist BSF 302146 is a potent inhibitor of neointimal and medial thickening in porcine saphenous vein-carotid artery interposition grafts. J Thorac Cardiovasc Surg 2004;127:1317-22

12. Wan S, Shukla N, Angelini GD, et al. Nitric oxidedonating aspirin (NCX 4016) inhibits neointimal thickening in a pig model of saphenous vein-carotid artery interposition grafting: A comparison with aspirin and morpholinosydnonimine (SIN-1). J Thorac Cardiovasc Surg 2007;134:1033-9.

13. Wan S, Shukla N, Yim AP, et al. Orally administered penicillamine is a potent inhibitor of neointimal and medial thickening in porcine saphenous vein-carotid artery interposition grafts. J Thorac Cardiovasc Surg 2007;133:494-500.

14. Shukla N, Wan S, Angelini GD, et al. Low nanomolar thapsigargin inhibits the replication of vascular smooth muscle cells through reversible endoplasmic reticular stress. Eur J Pharmacol 2013;714:210-7.

15. Wan S, George SJ, Nicklin SA, et al. Overexpression of p53 increases lumen size and blocks neointima formation in porcine interposition vein grafts. Mol Ther 2004;9:689-98.

16. Kritz AB, Yu J, Wright PL, et al. In vivo modulation of Nogo-B attenuates neointima formation. Mol Ther 2008; 16:1798-804.

17. Baker AH, Yim AP, Wan S. Opportunities for gene therapy in preventing vein graft failure after coronary artery bypass surgery. Diabetes Obes Metab 2006;8:119-24.

18. George SJ, Wan S, Hu J, et al. Sustained reduction of vein graft neointima formation by ex vivo TIMP-3 gene 
therapy. Circulation 2011;124:S135-42.

19. Lopes RD, Hafley GE, Allen KB, et al. Endoscopic versus open vein-graft harvesting in coronary-artery bypass surgery. N Engl J Med 2009;361:235-44.

20. Souza DS, Bomfim V, Skoglund H, et al. High early patency of saphenous vein graft for coronary bypass harvested with surrounding tissue. Ann Thorac Surg 2001;71:797-800.

Cite this article as: Wan S, Cheng ZY. Taking care of the soldiers. J Thorac Dis 2018;10(Suppl 33):S4002-S4005. doi: 10.21037/jtd.2018.09.25
21. Souza DS, Johansson B, Bojö L, et al. Harvesting the saphenous vein with surrounding tissue for CABG provides long-term graft patency comparable to the left internal thoracic artery: results of a randomized longitudinal trial. J Thorac Cardiovasc Surg 2006;132:373-8.

22. Wan S. Has the time come for another breakthrough in surgical myocardial revascularization? Chin Med J 2009; 122:123-5. 